\title{
EDITORIAL
}

\section{Exploring the Work of Artists and Activists to Translate Research into Action and Foster Public Space Culture}

\author{
Luisa Bravo \\ City Space Architecture, Italy \\ luisa.bravo@cityspacearchitecture.org \\ Maggie McCormick, Fiona Hillary \\ RMIT University, School of Art, Australia \\ maggie.mccormick@rmit.edu.au | fiona.hillary@rmit.edu.au
}

In November 2018 The Journal of Public Space published the special issue 'Art and Activism in Public Space', that was launched in Barcelona at RMIT Europe headquarters, during the SkypeLab Sympolab (http://www.skypelab.org/), and was introduced by Estanislau Roca Blanch, Vice Rector for Infrastructure and Architecture at the Universitat Politècnica de Catalunya. The issue collected a selection of projects of invited artists and activists, from Italy, Spain, Germany, United States, South America, Africa and Australia, and was the result of collaboration between City Space Architecture and RMIT University in Melbourne, Australia. The Journal of Public Space is an academic, double blind peer reviewed journal, so the main aim is to publish quality outcomes of academic research. Also, The journal is devoted to the implementation of the New Urban Agenda, adopted at the Habitat III conference in Quito (2016), and to the dissemination of the Agenda 2030 for Sustainable Development, in regard of public space. Then the mission of The Journal of Public Space, as an open forum for public space knowledge, is to translate research into action and foster public space culture, with the ambition to help defining city-wide public space strategies for local governments.

The work of artists and activists all around the world is making clear that a human-oriented approach with short-term but context-sensitive interventions can have a long-term impact in specific areas where the lack or underdevelopment of public space strongly influence everyday life of large populations, especially in the Global South. Artists and activists are playing with imagination, redefining urban scenarios and opening to a different level of consciousness of places, based on a different way to approach, see and understand everyday urbanism of different places. They are able to produce outcomes, through visual interpretations or temporary interventions that strongly and powerfully deliver the message of what public space could be, and reinforce the sense of pride, civic identity and social cohesion among communities.

The special issue 'Art and Activism in Public Space' published in 2018 received an overwhelming success: according to our data and statistics, it gave a significant boost to the journal, so we decided to start a series on this topic. The Journal of Public Space is interested to embed artists and activists' research work in the discussion on public space, highlighting the importance of on-the-ground observations and human-oriented thinking for the future of cities. In May 2019 City Space Architecture entered into an agreement with RMIT University in Melbourne, Australia, which is a leader in public space art practice. We then started to work on the present issue, inviting artists and activists and later made a selection of projects from 
Italy, Slovenia, Cyprus, Kenya, Brazil and Kurdistan. The issue features also a special section with artists who have come through the MAPS - Master of Arts (Art in Public Space) program at RMIT University in Melbourne, Australia. The MAPS program engages with multidisciplinary practice based creative inquiry to explore key issues confronting global public environments. By making connections between theory, art practice and everyday life the program explores issues critical to local and international cultural, political and social debates and recognises the important role public space plays as a forum for these exchanges. The program is designed around work-integrated learning through local and international site and location specific contexts, to develop conceptual and practical skills and to undertake collaborative and individual projects. MAPS draws together a cohort of those with skills in visual practice, performance, video, sound, creative arts, writing, design, architecture, fashion and curatorial and cultural management fields with ambitions to develop and extend skills within their existing career or to move into spatial and social practice in and about public space. MAPS is closely aligned with the RMIT School of Art's research group CAST - Contemporary Art and Social Transformation, as a hub for artistic practices that intersect with issues of equity, access and democracy and radical ways of knowing and being, with an interest in the public sphere, the intersection of human and nonhuman forces, global indigeneity and the role of education as a change-agent. RMIT's partnership with City Space Architecture and The Journal of Public Space enhances MAPS ambitions to provide quality education within an internationally networked environment.

We are planning to publish an 'Art and Activism in Public Space' issue every year in November. In February 2020 we will publish a call for expression of interest on our website, and we will later select a number of relevant projects to be published in November 2020.

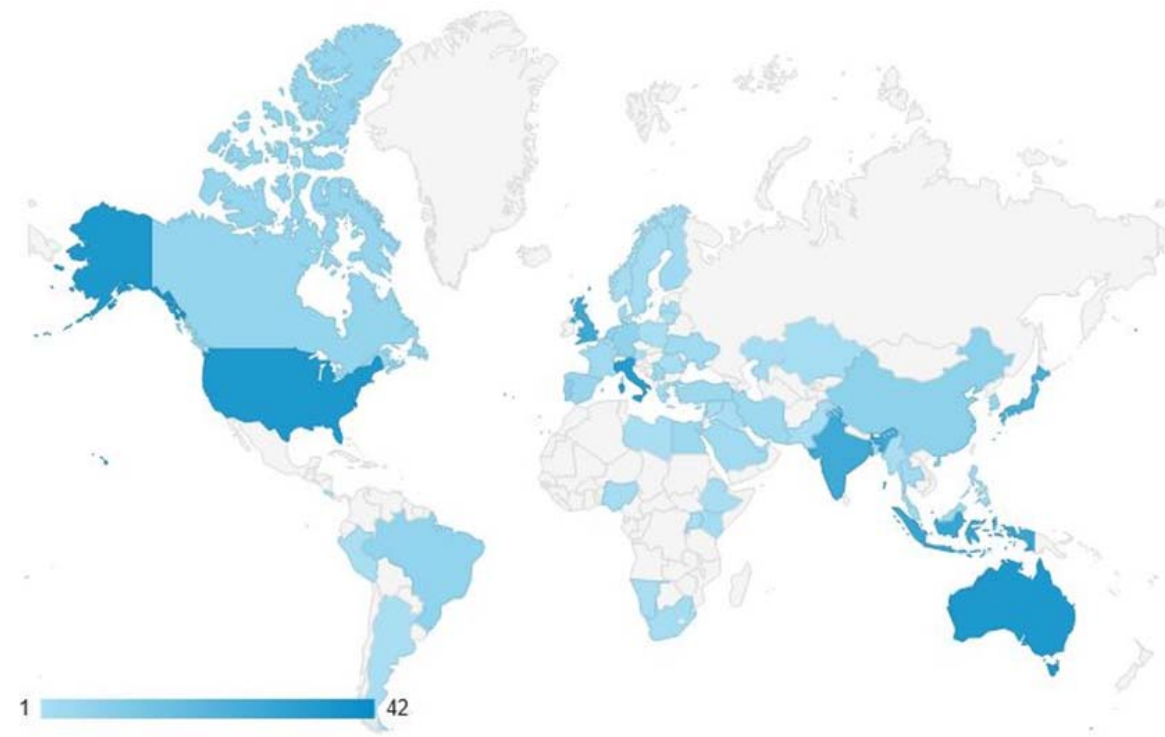

Figure I. Impact of the issue 'Art and Activism in Public Space' published in November 20I8.

To cite this article:

Bravo, L., McCormick, M. Hillary, F. (2019). Exploring the Work of Artists and Activists to Translate Research into Action and Foster Public Space Culture. The Journal of Public Space, 4(3), I-2, DOI 10.3289I/jps.v4i3. I 230 